\title{
PROTEÇÃO CONSTITUCIONAL DO PATRIMÔNIO HISTÓRICO NA ÓTICA DO FEDERALISMO BRASILEIRO
}

\author{
Constitutional protection of historical patrimony in the perspective \\ of Brazilian federalism
}

\section{Marcelo Schenk Duque}

Doutor em Direito do Estado pela UFRGS/ed. Ruprecht-Karls-Universität Heidelberg, Alemanha. Pesquisador convidado junto ao Europa Institut da Universidade de Saarland, Alemanha. Professor do Programa de Pós-Graduação em Direito stricto sensu da UFRGS. Coordenador Acadêmico do Curso de Especialização em Direito do Estado da UFRGS. Professor titular da Escola da Magistratura Federal do Estado do Rio Grande do Sul - ESMAFE/RS; Professor de diversos cursos de Pós-graduação lato sensu da UFRGS, PUC/RS, FEMARGS, FESDEPRS, FMP, entre outros. Professor da Faculdade Dom Bosco de Porto Alegre. Professor da Escola Superior de Advocacia da OAB/RS. Membro da Associação LusoAlemã de Juristas: DLJV - Deutsch-Lusitanische Juristenvereinigung.

\section{Resumo}

A proteção do patrimônio histórico é uma das vertentes do chamado direito fundamental à identidade cultural. Na condição de direito fundamental ligado à personalidade, consolidado em um Estado Federal, coloca-se a questão: como está regulada a proteção constitucional do patrimônio histórico no marco das regras e técnicas de repartição de competências adotadas pela Constituição Federal de 1988? A resposta a essa questão leva ao estudo do princípio da subsidiariedade, inserido no núcleo da forma federativa de Estado. O estudo parte do geral para o particular, com base do método indutivo de pesquisa, tomando como técnica a revisão bibliográfica e jurisprudencial.

Palavras-chave: Patrimônio histórico. Direitos fundamentais. Forma federativa de Estado. Princípio da subsidiariedade

\section{Abstract}

The protection of historical patrimony is one of the aspects of the so-called human right to cultural identity. As a human right linked to the personality, consolidated in a Federal State, the following question can be asked: how is the constitutional protection of historical patrimony regulated under the rules and power-sharing techniques adopted by the Federal Constitution of 1988 ? The answer to this question leads to the study of the principle of subsidiarity, inserted in the nucleus of the federative form of State. The study starts from the general to the particular, based on the inductive method of research, taking as a technique the bibliographical and jurisprudential review.

Keywords: Historical patrimony. Human rights. Federal State. Principle of subsidiarity

\section{Sumário}

1. Introdução; 2. Topografia constitucional; 3. A proteção do patrimônio histórico como direito da personalidade; 4 . A proteção do patrimônio histórico no quadro da repartição de competências administrativas da federação; 5 . A proteção do patrimônio histórico no quadro da repartição de competências legislativas da federação; 6.0 peculiar papel dos Municípios na proteção do patrimônio histórico; 7. A mitigação da doutrina do interesse predominante, no quadro da competência legislativa municipal para proteção do patrimônio histórico; 8. O princípio da subsidiariedade como indutor da proteção do patrimônio histórico na federação; 9. Considerações finais; 10. Notas; Referências. 


\section{INTRODUÇÃO}

A crise da pós-modernidade pode ser analisada com uma crise de desconfiança do próprio direito, em seus instrumentos e instituições, o que aponta para a necessidade de uma reação (MARQUES, 2016, p. 191). Dentro desta desconfiança, está a dúvida quanto à efetividade do direito na proteção do patrimônio histórico-cultural, típico direito fundamental de terceira geração, marcado pela transindividualidade. A relevância do tema reside no fato de que a doutrina, em geral, pouca atenção tem conferido ao capítulo das competências federativas associadas à proteção do patrimônio histórico nacional.

Nesta linha, o objetivo do estudo é verificar como está regulada a proteção constitucional do patrimônio histórico à luz da forma federativa de Estado, considerando as regras e as técnicas de repartição de competências adotadas pela Constituição Federal de 1988 e compreender a influência do princípio da subsidiariedade na realização desse dever estatal de proteção, de hierarquia constitucional, para efeito de delimitação das respectivas competências dos entes federativos. Recorre-se, para tanto, à técnica de pesquisa baseada na revisão bibliográfica e jurisprudencial, adotando-se, como marco referencial teórico, contribuição de autores nacionais e estrangeiros, que lograram êxito em estudar o complexo tema das competências estatais no quadro federativo.

\section{TOPOGRAFIA CONSTITUCIONAL}

A proteção constitucional do patrimônio histórico está prevista em diferentes âmbitos da Constituição Federal. No catálogo de direitos fundamentais a menção direta ocorre na previsão do instituto da ação popular, meio hábil, dentre outros, à proteção do patrimônio histórico e cultural contra atos lesivos praticados por pessoas públicas ou privadas. Aqui a Constituição reforça o caráter democrático do instituto, ao atribuir sua legitimidade ativa a qualquer cidadão, independentemente de foro por prerrogativa de função da autoridade ré. ${ }^{1}$ Segundo a doutrina clássica, possui a natureza jurídica de disposição assecuratória, pois, em defesa dos direitos, limita o poder (BARBOSA, 1891, p. 181).

De forma específica, e mais detalhada, a Constituição trata da questão no seu título VIII, denominado "da ordem social", cuja disposição geral tem como base o primado do trabalho, e como objetivo o bem-estar e a justiça sociais. ${ }^{2}$ À primeira vista, parece ser na noção de bem-estar que a proteção do patrimônio histórico adquire maior ponto de contato com a ordem social. Todavia, quando se evolui na leitura do texto constitucional, observa-se que o constituinte reservou um capítulo próprio, dentro do referido título, para a proteção do patrimônio histórico-cultural, denominado "da cultura", onde assume o dever fundamental de garantir a todos o pleno exercício dos direitos culturais e acesso às fontes da cultura nacional, além do dever de apoiar e incentivar a valorização e a difusão das manifestações culturais como um todo. ${ }^{3}$ Ato contínuo, a Constituição apresenta uma definição exemplificativa do chamado patrimônio cultural brasileiro, onde inclui os conjuntos urbanos e sítios de valor histórico, paisagístico, artístico, arqueológico, paleontológico, ecológico e científico. ${ }^{4}$ É por essa razão que a ligação da proteção do patrimônio histórico com o bem-estar é apenas uma das faces da moeda. Trata-se de garantia atrelada à própria liberdade de desenvolvimento da personalidade do ser humano. 


\section{A PROTEÇÃO DO PATRIMÔNIO HISTÓRICO COMO DIREITO DA PERSONALIDADE}

Na ordem constitucional brasileira, a proteção do patrimônio histórico se dá em dupla perspectiva, pois engloba tanto uma dimensão material quanto imaterial do seu objeto de proteção. Neste sentido, a tutela do patrimônio histórico é apenas uma das vertentes do chamado direito fundamental à identidade cultural. Essa é a razão pela qual o art. 215 da Constituição estabelece que constituem patrimônio cultural brasileiro os bens de natureza material e imaterial, tomados individualmente ou em conjunto, portadores de referência à identidade, à ação, à memória dos diferentes grupos formadores da sociedade brasileira.

Ciente dessa dupla perspectiva, pode-se afirmar que a ligação da proteção do patrimônio histórico com os direitos da personalidade repousa na compreensão de que a liberdade de ação geral prevista de forma ampla na Constituição, por normas de natureza diversa, é considerada uma espécie de direito fundamental mãe (Muttergrundrecht), a partir do qual vários outros direitos fundamentais fluem (BLECKMANN, 1997, p. 87). Em particular, a possibilidade de se desenvolver a personalidade a partir do acesso às fontes culturais traduz-se em ideal a ser buscado pelo próprio Estado de direito, onde a liberdade afirma-se como valor básico. Isso se deixa fundamentar pela própria compreensão do ser humano a partir das suas dimensões básicas, em particular, no tema ora investigado, na dimensão estética ou artística do ser.

Essa dimensão informa que a pessoa humana depende da ordenação dos seus sentimentos e das suas emoções, para o equilíbrio da sua personalidade, especialmente em face das pressões que sofre do mundo exterior (SOUZA JUNIOR, 2002, p. 24). A conclusão que se pode tecer é que uma vida pautada pela dignidade passa por uma vida com acesso às fontes culturais, de modo que o dever do Estado de proteger o patrimônio histórico contribui para a própria preservação da dignidade humana. Trata-se de afirmação que encontra arrimo na doutrina, a partir da noção de que a dignidade humana atua como critério para a construção de um conceito materialmente aberto de direitos fundamentais na ordem constitucional (SARLET, 2012b, p. 118).

É por essa razão que a proteção do patrimônio cultural está inserida, na doutrina constitucional, no grupo de direitos denominados de terceira dimensão ou geração, aspecto consagrado pela doutrina e pela jurisprudência. ${ }^{5}$ Entre nós, Paulo Bonavides (2002, p. 522s.) afirma que tais direitos são caracterizados por altíssimo teor de humanismo e universalidade, motivo pelo qual tendem a cristalizarem-se, na modernidade, como direitos que não visam especificamente à proteção dos interesses de indivíduos isoladamente considerados, já que têm por destinatário o próprio gênero humano, entre os quais a proteção do patrimônio comum da humanidade afirma-se como exemplo. Esse caráter transindividual, que surge da titularidade coletiva, por vezes indefinida e indeterminável (SARLET, 2012a, p. 49), faz com que esses direitos devam ser pensados do ponto de vista de políticas públicas abrangentes.

A moderna teoria dos direitos fundamentais consagra diferentes funções para esses direitos (DUQUE, 2014, p. 69ss.). Ao tema da preservação do patrimônio histórico interessa, sobretudo, a função de proteção. Efetivamente, quando se fala em um âmbito protegido por 
um direito fundamental, tem-se em mente um espaço da vida no qual o direito fundamental desenvolve uma função protetiva (LÜBBE-WOLFF, 1988, p. 26), que impõe um dever de zelo pelo Estado e um dever de abstenção por particulares, no sentido de uma verdadeira eficácia horizontal (DUQUE, 2013, p. 133ss.). Em outras palavras, não é dado ao Estado, nem a particulares, violar o âmbito protegido pelos direitos fundamentais em seu conteúdo essencial. Não é à toa que a Constituição, a tratar da questão, estabelece que cabe ao Poder Público, com a colaboração da comunidade, promover e proteger o patrimônio cultural brasileiro, por meio de inventários, registros, vigilância, tombamento e desapropriação, além de outras formas de acautelamento e preservação, ${ }^{6}$ além de ordenar ao legislador, por meio de reserva legal expressa, a edição de normas que contenham punições àqueles que causem danos e ameaças ao patrimônio cultural. ${ }^{7}$

Aqui abre-se uma conexão para o estudo dos deveres de proteção do Estado, que ganhou grande desenvolvimento da doutrina alemã (DUQUE, 2013, p. 333ss.). Nesta oportunidade, pelas delimitações da presente investigação, não se adentrará na referida teoria. Sem embargo, deixa-se registrado que a decisão de "como" um dever de proteção deve ser cumprido é assunto, em primeiro lugar, do legislador e a partir daí dos órgãos competentes que integram a administração pública (STARCK, 1994, p. 67). E isso, evidentemente, vale para a questão da preservação do patrimônio histórico nacional. Para a presente investigação, essa constatação tem caráter decisivo: o estudo da proteção constitucional do patrimônio histórico adquire predominância no capítulo da repartição de competências constitucionais, matéria ínsita à forma federativa de Estado.

\section{A PROTEÇÃO DO PATRIMÔNIO HISTÓRICO NO QUADRO DA REPARTIÇÃO DE COMPETÊNCIAS ADMINISTRATIVAS DA FEDERAÇÃO}

A matéria está contida no título III da Constituição Federal, no âmbito da organização do Estado. Com efeito, é justamente nesse título que a Constituição de 1988 dedica maior atenção à proteção do patrimônio histórico, já que o consagra em diferentes passagens, com complexas implicações de responsabilidade estatal na ordem constitucional. Inicia-se afirmando que os sítios arqueológicos e pré-históricos se constituem em bens da União. ${ }^{8}$ Segue no tópico das chamadas competências concorrentes ou compartilhadas, espécies de competências administrativas, vale dizer, tarefas estatais, que devem ser exercidas em conjunto pela União, Estados e o Distrito Federal. Ali há expressa previsão para a responsabilidade dos entes federativos na execução das tarefas e encargos que dizem respeito à proteção dos documentos, obras e outros bens de valor histórico, artístico e cultural, assim como dos monumentos, as paisagens naturais notáveis e os sítios arqueológicos. ${ }^{9}$ Da mesma forma, há ordem de vinculação dos entes às obrigações inerentes à tomada das providências necessárias a impedir a evasão, destruição e a descaracterização de obras de arte e de outros bens de valor histórico, artístico ou cultural ${ }^{10}$.

Ao tratar da preservação do patrimônio histórico sob a perspectiva de competências legislativas concorrentes ou compartilhadas, a Constituição de 1988 deu um passo importante na consolidação de um modelo de federalismo cooperativo, como será visto a seguir. Infelizmente, esse passo constituiu-se em exceção e não na regra. Do conjunto da obra 
federativa brasileira tem-se um verdadeiro federalismo centralizador, o que a doutrina costuma denominar de centrífugo (HORTA, 2003, p. 306s.). Ao inclinar-se pelo fortalecimento do poder federal, convergindo excessivamente para o centro, acaba por se tornar ineficaz, no instante em que concentra poderes excessivos na União, particularmente no que diz respeito ao chamado federalismo financeiro, verdadeiro calcanhar de Aquiles da Federação. Trata-se de verdadeira contradição, levando-se em conta que um dos objetivos que levou ao desenvolvimento da ideia federativa, como construção jurídico-constitucional, foi justamente dificultar a acumulação de poder em um só órgão (DALARI, 2012, p. 256). É por esse motivo que a doutrina especializada acerta ao afirmar que o Brasil consagrou o nome (República Federativa), sem a realidade (REVERBEL, 2012, p. 131ss.).

Não obstante os problemas que atingem a federação brasileira, cumpre analisa-la em aspectos mais positivos. Interessante, aqui, foi a técnica adotada pelo legislador constituinte. Em que pese atribuir aos Municípios dentro da organização político-administrativa da República a condição de ente federativo, ao lado da União, dos Estados e do Distrito Federal, ${ }^{11}$ a Constituição de 1988 optou por não os incluir, de forma literal, no rol das competências administrativas concorrentes, previstas no art. 23. Todavia, isso não significa que os Municípios deixaram de receber encargos no âmbito das referidas competências administrativas concorrentes. Isso porque, em local próprio, quanto a Constituição refere-se aos Municípios, ela expressamente determina que a eles cabe promover a proteção do patrimônio histórico-cultural local, observada a legislação e a ação fiscalizadora federal e estadual. ${ }^{12}$ Ou seja: em matéria de proteção do patrimônio histórico, os Municípios detêm encargos de forma concorrente ou compartilhada com os demais entes federativos.

\section{A PROTEÇÃO DO PATRIMÔNIO HISTÓRICO NO QUADRO DA REPARTIÇÃO DE COMPETÊNCIAS LEGISLATIVAS DA FEDERAÇÃO}

Ainda no âmbito da organização do Estado, a matéria encontra previsão junto às chamadas competências legislativas concorrentes. Trata-se de assunto de inegável complexidade, pois vincula a ação do Poder Legislativo em diferentes níveis federativos, de forma concatenada, aspecto que, não raro, conduz ao juízo de inconstitucionalidade formal de determinadas proposições legislativas, sobretudo em face de eventuais conflitos que levam à usurpação de competência do ente central, pelos entes periféricos. Não é por menos que o STF há muito vem debatendo e buscando definir os limites das chamadas competências legislativas, dentro do marco constitucional. Diga-se de passagem, não é um problema exclusivamente brasileiro. Mesmo no Direito estrangeiro, inúmeras são as tentativas de se agregar uniformidade às decisões constitucionais, em matéria de competências legislativas privativas e concorrentes, inclusive à luz de estudos comparados (KEWENIG, 1968, p. 433ss.).

Falar em distribuição de competências legislativas na federação é um problema que passa pela necessidade de se estabelecer as relações recíprocas entre os entes federativos, o que pode ser cotejado por meio de diversas faces (AZAMBUJA, 2008, p. 403). No âmbito da proteção do patrimônio histórico, o tema se agrava em função de percepções diversas quanto ao que proteger, como proteger, em um país de dimensões continentais marcado pelo multiculturalismo. Particularmente, neste tipo de sociedade, diferentes con- 
cepções de mundo não raro ingressam em conflito. Levando-se em conta que conflitos de interesse frequentemente englobam conflitos de direito (FERREIRA FILHO, 2011, p. 50), a Constituição deve funcionar como um elemento agregador, unificando a sociedade para consensos mínimos, que não podem ser abandonados pelas diferenças setoriais, clivagens ideológicas, dentre outras, que a separam em seguimentos determináveis. Dentre esses consensos, deve haver lugar para o fato de que o patrimônio histórico de uma nação é algo indisponível a ação de grupos ou ideologias.

Um dos focos de uma sociedade multicultural é a proteção de minorias, ante o poder da maioria (MAHONEY, 2011, p. 127), ação que passa pela noção de dignidade humana (OLIVEIRA JUNIOR, 2010, p. 3ss.) que, por sua vez, fundamenta uma garantia de liberdade de ação geral, que normalmente é retratada na doutrina como uma garantia de livre desenvolvimento da personalidade (DUQUE, 2014, p. 248). Precisamente neste ponto que a técnica de repartição de competências legislativas concorrentes ganha destaque na proteção do patrimônio histórico. O motivo, para tanto, está no seu caráter flexível que, quando bem exercido, impede que o crescimento progressivo dos poderes da União, ente central, venha a absorver ou sufocar as competências dos entes periféricos (HORTA, 1981, p. 17). Assim, interesses diversos, situados em regiões igualmente diversas, tendem a coexistir graças à proteção que assuntos de caráter local recebem da Constituição, sem que isso afaste regulamentos de caráter geral. Não é por menos que liberdade e democracia acabam, invariavelmente, por exercer influência sobre a maior ou menor amplitude da descentralização territorial do poder político e administrativo em uma nação (BONAVIDES, 2002, p. 313).

Nesse prisma, é precisamente a existência de interesses gerais e regionais reconhecidos pela Constituição que delimita esferas de competências tanto em âmbito global quanto regional, aptas a criarem direitos e deveres recíprocos, ditando as regras de convivência entre os entes da federação (ATALIBA, 1969, p. 60). Assim, a moderna ideia de federalismo atribui aos entes periféricos instrumentos de ação administrativa e legislativa próprios, que sem prejuízo do comando da União, indispensável ao desenvolvimento nacional e ao exercício dos poderes constituídos (HORTA, 1981, p. 17), permite a tomada de decisões mais próximas da realidade da vida, mais perceptível do ponto de vista local do que central.

Na acepção de Konrad Hesse (1999, Rdn. 219), o conceito de federalismo expressa a livre unificação de totalidades políticas diferenciadas, com os mesmos direitos, por regra regionais, que dessa maneira devem ser unidas para cooperação comum. Não se trata, portanto, de uma doutrina fechada ou de um sistema; é, antes, um princípio conformador situado à frente da sociedade, que nessa condição não está livre de antinomias, frente a uma variedade de tendências de igualdade social e diversidade política, que não são necessariamente passíveis de integração (STERN, 1984, p. 660ss.).

Na prática, isso leva à uma eficaz proteção do patrimônio histórico à luz de valores tanto nacionais quanto regionais. O que é de importância para o norte, não pode ser desconsiderado apenas e tão somente porque não se reveste de valor culturalmente imerso na sociedade do sul do país, e vice-versa. Portanto, o caminho de ouro da federação passa, inegavelmente, pela noção de que a obtenção da unidade passa pela proteção da diversidade, circunstância que assegura a liberdade da nação por intermédio da distribuição de 
poder e de responsabilidades entre os diferentes níveis da federação (ELLWEIN, 1996, p. 44ss.). Dito de outro modo: e respeitando o patrimônio cultural do próximo, que o meu será respeitado.

\section{O PECULIAR PAPEL DOS MUNICÍPIOS NA PROTEÇÃO DO PATRIMÔNIO HISTÓRICO}

Na realidade da Constituição de 1988, a proteção do patrimônio histórico ganha destaque pela inserção dos Municípios do âmbito das competências legislativas concorrentes. Assim como se passa frente às competências administrativas compartilhadas, o legislador constituinte optou por não incluir os Municípios no caput do artigo que trata das competências legiferantes comuns. ${ }^{13}$ Entretanto, mais uma vez, em local específico, a Constituição atribui aos Municípios a competência para suplementar a legislação federal e a estadual no que couber. ${ }^{14}$ Ou seja, os Municípios também exercem competências legislativas sobre as matérias do art. 24 da Constituição, no âmbito da suplementação, o que implica completar a legislação da União e dos Estados, sem, contudo, contrariá-la.

Note-se que ainda que inexistisse legislação federal ou estadual em face dos assuntos cunhados no referido art. 24 da Constituição, isso não representaria impeditivo insuperável para a atuação legislativa dos Municípios nessas matérias de competência comum. Isso porque a Constituição consagra a famosa cláusula do interesse predominante (BRANCO, 2017, p. 879), no momento em que atribui aos Municípios competência para "legislar sobre assuntos de interesse local". ${ }^{15}$ Não se pode perder de vista, sob pena de tornar o debate superficial, que sempre haverá dúvidas quanto à real extensão do conceito de "interesse local", cabendo à doutrina e à jurisprudência um esforço hermenêutico no sentido de definir seus contornos, tendo em vista a segurança jurídica. Isso porque a segurança jurídica, para além de um valor positivado, afirma-se como uma noção inerente à própria ideia de Direito, levando-se em conta que sem um mínimo de certeza e de atitude voltada ao rechaço à arbitrariedade, não se pode, a rigor, falar em sistema jurídico (ÁVILA, 2011, p. 85ss.).

De fato, muitas vezes é difícil definir a realidade apenas com palavras. As tensões entre a pretensão de normatividade da Constituição, as circunstâncias de fato e a inércia e resistência do chamado status quo (BARROSO, 2011, p. 220) tornam a luta pela efetivação da Constituição um desafio e tanto. A experiência constitucional revela que, ao fim e ao cabo, tudo parece conduzir para um velho dilema: o problema da compatibilidade entre o direito constitucional (Verfassungsrecht) e a realidade constitucional (Verfassungswirklichkeit), na medida em que as constituições não podem modificar diretamente a realidade, mas apenas indiretamente influenciá-la (GRIMM, 1991, p. 17ss.). Isso significa que o debate que ocorre entre o conteúdo inerente às diferentes nomenclaturas utilizadas para descrever a autonomia municipal ao longo dos ciclos constitucionais brasileiros, como a difundida a expressão "peculiar interesse", mencionada no art. 16, II da Constituição de 1967, ${ }^{16}$ em comparação com a expressão "interesse local", consagrada pelo art. 30, I da Constituição de 1988, parecem ser assuntos de menor importância, ao menos no debate inerente ao presente estudo.

Isso porque, como visto, a Constituição vigente é clara ao atribuir aos Municípios, de forma concorrente com a União e os Estados, a promoção e a proteção do patrimônio histó- 
rico-cultural local. Certeira, portanto, é a observação de Fernanda Dias Menezes de Almeida (2013, p. 99), quando afirma que a mera mudança da literalidade do dispositivo não equivale, necessariamente, à mudança do espírito da norma constitucional. Os Municípios, de fato, representam excelente mecanismo de descentralização territorial de competências políticas e administrativas, considerando que o respectivo grau de descentralização é proporcional às chances de participação do cidadão da formação da vontade estatal. Nesse sentido, a descentralização contribui para elevar o nível democrático de uma nação (TAVARES, 2018, p. 885). É por essa razão que Raul Machado Horta (1982, p. 107), sempre atento às questões federativas, alertou que após um longo período de experiência constitucional republicana, o Município tronou-se uma presença constante no quadro das instituições nacionais e converteu-se em grande tema de debates e estudos constitucionais. No marco da proteção do patrimônio histórico, isso não é diferente.

\section{A MITIGAÇÃO DA DOUTRINA DO INTERESSE PREDOMINANTE, NO QUADRO DA COMPETÊNCIA LEGISLATIVA MUNICIPAL PARA PROTEÇÃO DO PATRIMÔNIO HISTÓRICO}

O que pode ser ainda discutido, é que a competência legislativa municipal, ainda que efetivamente busque proteger interesse local, deve guardar respeito às normas constitucionais vigentes, em particular não se contrapondo às determinações nacionais e estaduais, considerando seu caráter de suplementação. A doutrina tradicional costumava levantar o chamado princípio da predominância do interesse, a partir do seguinte raciocínio: caberia à União legislar sobre as matérias de interesse predominante geral, nacional, aos Estados-membros sobre as de predominante interesse regional e aos Municípios sobre as de interesse local (SILVA, 2005, p. 478), o que acaba levando ao áspero debate em torno do conceito de norma geral (CARVALHO PINTO, 1949, p. 41). De fato, é muito difícil estabelecer um conceito de norma geral e essa dificuldade não reina apenas no campo da proteção do patrimônio histórico. Razoável é definir tais normas como bases ou diretrizes, expressão de princípios, que por seu elevado grau de abstração acabam indicando uma direção a ser seguida, sem fixar, contudo, uma única opção.

É por essa razão que a doutrina costuma referir que princípios são mandamentos de otimização, tendo em vista que ordenam que algo seja realizado na maior medida possível, de acordo com as possibilidades jurídicas e reais existentes no caso concreto, razão pela qual se caracterizam pelo fato de poderem ser cumpridos em graus distintos, o que equivale dizer, em maior ou em menor grau (ALEXY, 1994, p. 75s.). São, por conseguinte, normas de caráter finalístico, cuja aplicação exige uma correta avaliação entre o estado de coisas a ser promovido e os efeitos que decorem da conduta considerada necessária à sua promoção (ÁVILA, 2006, p. 78s.). Por tais motivos, resta facilitada a tarefa quando se definem as normas gerais pelo critério negativo: indicar os traços de uma norma que não é geral, por ser particularizante ou complementar. Assim, quando a norma transmite comandos que descem a particularizações, típicas ao atendimento de peculiaridades locais, de norma geral não se tratará (FERREIRA FILHO, 2011, p. 184s.).

Na temática da proteção constitucional do patrimônio histórico, o comando constitucional que atribui à União, Estados e Distrito federal a competência concorrente para legislar 
sobre a proteção ao patrimônio histórico, cultural, artístico, turístico e paisagístico, ${ }^{17}$ deve ser interpretado e aplicado no contexto das regras de solução de conflitos legislativos previstas nos parágrafos do referido artigo: no âmbito da legislação concorrente, a competência da União limitar-se-á a estabelecer normas gerais; ${ }^{18}$ a competência da União para legislar sobre normas gerais não exclui a competência suplementar dos Estados; ${ }^{19}$ inexistindo lei federal sobre normas gerais, os Estados exercerão a competência legislativa plena, para atender a suas peculiaridades; ${ }^{20}$ e a superveniência de lei federal sobre normas gerais suspende a eficácia da lei estadual, no que Ihe for contrário. ${ }^{21}$

E aos Municípios, como visto, é reconhecida competência para suplementar a legislação federal e a estadual no que couber, ${ }^{22}$ ou seja, complementar as leis dos entes federativos superiores, de forma a tender as suas peculiaridades. Trata-se, portanto, do quadro de competências legislativas concorrentes não cumulativas, pelo fato de a Constituição estabelecer uma repartição de ordem vertical, reservando ao ente central o poder de fixar as mencionadas normas gerais, deixando aos demais a competência para complementá-las, ciente de quem supre um vácuo ${ }^{23}$, acaba por complementar o ordenamento (FERREIRA FILHO, 2011, p. 182).

O grande problema da interpretação das regras constitucionais de repartição de competências é que não se pode mais olhar, fixamente, para o princípio da predominância do interesse como algo fechado. Trata-se, a toda evidência, da expressão de um raciocínio lógico, mas que não afasta uma dificuldade, a ele inerente: no Estado moderno se torna cada vez mais difícil discernir o que é interesse nacional ou geral, dos interesses regionais ou locais (SILVA, 2005, p. 478), considerando a inter-relação de causas e consequências que dizem respeito aos tempos atuais. Neste quadro, a questão, desde cedo, colocava-se essencialmente como um problema de interpretação dentro de uma concepção integrativa da hermenêutica (SOUZA, 1953, p. 15).

Não é por acaso que a tradicional jurisprudência do STF também recorreu à teoria de predominância de interesses, segundo a qual os interesses mais amplos (da União) devem prevalecer sobre os mais restritos (dos Estados e Municípios). Esse raciocínio vem se mantendo, ainda com variações distintas. De forma geral, o STF, ao se referir ao princípio da predominância do interesse, tem afirmado que:

\begin{abstract}
1. As regras de distribuição de competências legislativas são alicerces do federalismo e consagram a fórmula de divisão de centros de poder em um Estado de Direito. Princípio da predominância do interesse. 2. A Constituição Federal de 1988, presumindo de forma absoluta para algumas matérias a presença do princípio da predominância do interesse, estabeleceu, a priori, diversas competências para cada um dos entes federativos - União, Estados-Membros, Distrito Federal e Municípios - e, a partir dessas opções, pode ora acentuar maior centralização de poder, principalmente na própria União (CF, art. 22), ora permitir uma maior descentralização nos Estados-Membros e nos Municípios (CF, arts. 24 e 30 , inciso I). ${ }^{24}$
\end{abstract}

Um norte identificável é atrelar a extensão do interesse local, para efeitos de delimitação de competências legislativas suplementares, à manutenção dos respectivos regramentos no chamado conjunto harmônico com a disciplina estabelecida pelos demais entes federados. ${ }^{25}$ Contudo, a moderna concepção de federalismo cooperativo minimiza tal concepção, aspecto que, igualmente, tem recebido atenção do STF. O caso paradigma, 
aqui, é o que reconheceu a constitucionalidade de leis estaduais que proíbem o comércio de produtos fabricados à base de amianto. A controvérsia jurídica surgiu pelo fato de que a Lei federal $n^{\circ} 9.055 / 95$, em seu art. $2^{\circ}$, admite a industrialização do amianto da variedade crisotila (asbesto branco). Em contrapartida, algumas leis estaduais, no curso da competência legislativa concorrente para proteção do meio-ambiente ${ }^{26}$ passaram a proibir o comércio de produtos à base de amianto, em todas as suas variações.

Surgiu, assim, um conflito de competências legislativas, que em um primeiro momento passaram a sugerir a inconstitucionalidade formal das normas estaduais, pelo fato de serem consideradas mais restritivas que a legislação federal. A questão que se colocou, foi se uma norma estadual poderia restringir o conteúdo de norma federal, hipótese que contrariaria a noção de complementar ou suplementar o conteúdo da norma geral, já que, neste caso, se verifica uma negativa parcial de conteúdo: se uma lei federal admite uma variante de amianto, a lei estadual não poderia proibir seu emprego no todo.

A matéria ganhou destaque por ocasião do julgamento da ADI 3.356, que possuiu longa tramitação no STF. ${ }^{27}$ Reconheceu-se a improcedência da ação, ou seja, a constitucionalidade de lei estadual de conteúdo restritivo em relação à norma geral federal. Na fundamentação, merece destaque o voto proferido pelo Min. Edson Fachin, que desenvolve a tese de relativização da teoria do interesse predominante, no curso da avaliação dos limites conferidos pela Constituição aos Estados-membros, em matéria de competência legislativa concorrente. ${ }^{28} \mathrm{O}$ cerne da argumentação repousa em seis pontos:

1. A distribuição de competência entre os diversos entes federativos, à luz do federalismo cooperativo previsto pela Constituição não se satisfaz apenas com o princípio informador da predominância de interesses. Diante da existência de situações fáticas, a regra de circunscrever-se à territorialidade não resolve de forma plena a solução do conflito existente entre normas, pois é necessário eleger, entre os entes federativos envolvidos, qual circunscrição prevalecerá.

2. A ideia de federalismo cooperativo deve mitigar a noção em torno de uma concentração das principais competências federativas no ente central, de forma a enfrentar os problemas de aplicação que emergem do pluralismo que forma o Estado e a sociedade brasileira.

3. A resolução de conflitos federativos em matéria de legislação concorrente deve ser buscada à luz do princípio da subsidiariedade, segundo o qual o poder sobre determinada matéria deve ser exercido pelo nível governamental que possa fazê-lo de forma mais apropriada e eficiente, ou seja, o ente político maior deve deixar para o menor tudo aquilo que este puder fazer com maior economia e eficácia. O aspecto formal do princípio seria destinado sobretudo aos poderes legislativos, pois exige que sejam fornecidos argumentos para demonstrar que a legislação deve ser editada de modo uniforme pelo ente central, critério apto a transmudar o enfoque a ser dado pelo Poder Judiciário: em vez de investigar qual competência o ente detém, se deveria investigar como o ente deve exercê-la.

4. O princípio da subsidiariedade deve ser complementado pelo da proporcionalidade, no sentido de sempre respeitar uma rigorosa adequação entre meios e fins. Assim, a inter- 
pretação conjunta da subsidiariedade e da proporcionalidade tende a consagrar um aspecto material no quadro dos problemas que envolvem a distribuição de competências legislativas na federação, fundamentando uma presunção de autonomia em favor dos entes menores, para a edição de leis que resguardem seus interesses.

5. Faz-se necessário que não apenas a legislação federal se abstenha de intervir desproporcionalmente nas competências locais, como também que, no exercício das competências concorrentes, a interferência das legislações locais na regulamentação federal não desnature a restrição ou a autorização claramente indicada.

6. Embora a competência para a produção, o consumo, a proteção do meio ambiente e a proteção e defesa da saúde seja concorrente, seria inconstitucional que o efeito da legislação geral editada pela União pudesse aniquilar totalmente as competências dos Estados e dos Municípios, ciente de que a Constituição consagra o princípio da precaução e o disposto no seu art. 225, $\S 3^{\circ}$, determina que o Poder Público deve agir com extrema cautela sempre que a saúde pública e a qualidade ambiental puderem ser afetadas por obra, empreendimento ou produto nocivo ao meio ambiente. ${ }^{29}$

Com base nesses argumentos, as leis estaduais consideradas mais restritivas que a lei geral em matéria de competências concorrentes foram consideradas constitucionais. Para a solução de eventuais conflitos legislativos que envolvam a proteção do patrimônio histórico nos diferentes níveis da federação, a discussão trazida no caso do amianto crisotila é modelar. Isso porque pode potencializar a edição de leis estaduais ou municipais que possuam conteúdo mais rigoroso para a proteção do patrimônio histórico local, em relação à proteção oferecida pelo direito federal.

A saída, portanto, está na compreensão do federalismo cooperativo, que parte da ideia de otimização de esforços e racionalização de recursos, visando à cooperação, ente os entes federados, na execução das tarefas, dos programas, das metas de governo, onde os mecanismos de racionalização dos procedimentos, voltados ao bem comum, são muito valorizados. A noção de um federalismo cooperativo gera uma descentralização de encargos quanto a matérias de grande relevância social, que não devem ser prejudicadas por questões de limites de competência, dentro daquilo que se costuma denominar de cooperação federal como regime competencial substantivo (DUQUE, 2011, p. 343ss.). Esse ideal tende a ser mais facilmente atingido, quando as instituições políticas conformadoras da vida social são planejadas e executadas de forma conjunta, em benefício da comunidade, levando-se em conta aspectos e interesses comuns das partes envolvidas, um modelo orientado à moderação dos fins (MAUNZ, 1997, Rdn. 92ss.).

\section{O PRINCÍPIO DA SUBSIDIARIEDADE COMO INDUTOR DA PROTEÇÃO DO PATRIMÔNIO HISTÓRICO NA FEDERAÇÃO}

O federalismo marcado pela descentralização tem méritos insubstituíveis na moderação do poder político, na conservação da variedade regional e na vinculação dos habitantes à sua coletividade mais próxima (GRIMM, 2001, p. 149), o que, no fundo, é expressão do princípio da subsidiariedade. No foco da proteção do patrimônio histórico pelos diferentes entes da federação, a compreensão do princípio tem significado estratégico. Ele informa que 
a responsabilidade e o poder de decisão recaem, na federação, sobre a menor comunidade social, melhor capacitada para a solução dos problemas que lhe são submetidos, já que se observa, na menor unidade, uma primazia no marco de sua capacidade de prestação (BOYSEN, 2005, p. 114). Na conformação federativa propriamente dita, essa circunstância implica supremacia da comunidade mais estrita perante a mais ampla, à qual apenas cabem funções subsidiárias, o que pressupõe homogeneidade mínima dos membros, assim como uma diferença de sua individualidade, cuja garantia é condição da unidade do todo (HESSE, 1999, Rdn. 219). Logicamente, o tempo e a experiência na condução desse modelo, como vetor direcionado à sua efetividade, também não podem ser menosprezados, em particular na proteção do patrimônio histórico, onde o tempo é decisivo para a tomada de providências, sob pena de perdas irreparáveis.

Há quem sustente, inclusive, que a ideia da subsidiariedade não se trata de um princípio técnico-jurídico (Rechtstechnischesprinzip), mas sim de um princípio ético-jurídico (Rechtsethischesprinzip) (ISENSEE, 1968, p. 313s.), na medida que refletiria nos próprios degraus da organização social, afirmando-se como critério de delimitação das tarefas estatais. Na prática, a ideia de um federalismo cooperativo informa que uma ordem federativa adequada aos novos tempos não é mais tecida a partir do simples modelo aqui espaço do Estado, aqui espaço da União; ela é reiteradamente entrelaçada ao jurídico e à realidade constitucional (STERN, 1984, p. 664).

Em verdade, o ideal seria que a partir da Constituição fosse possível extrair uma exata noção do princípio da subsidiariedade, do ponto de visa das suas consequências jurídicas concretas. Mas, como o ideal não existe, cabe ao intérprete compreender, interpretar e aplicar o seu conteúdo (GADAMER, 1990, p. 312s.). Assim, constata-se que o princípio da subsidiariedade está fortemente ligado à função de integração, como garantia de preservação do próprio Estado federal (OETER, 1998, p. 566ss.). É claro que em determinados casos poderá se constatar certa tensão entre subsidiariedade e integração (ŠARČEVIĆ, 2000, p. 177). Entretanto, essa circunstância não tem o condão de afastar a estrita relação entre subsidiariedade e federalismo, já que esse é um princípio conformador à frente da sociedade (STERN, 1984, p. 660).

Tratar a delimitação das competências dos entes federados, no que tange à proteção do patrimônio histórico, à luz do princípio da subsidiariedade, implica considerar que tudo aquilo que o Município puder fazer - de forma eficaz - em matéria de preservação do patrimônio histórico, não deve ser repassado ou "empurrado", como se costuma dizer, ao Estado. Somente aquelas tarefas, cuja complexidade técnica e/ou financeira não possa ser conduzida a contento pelo Município, deverão ser repassadas para a responsabilidade do Estado. Em raciocínio cruzado, tudo aquilo que o Estado puder fazer - e bem feio - não deve ser repassado para a União, de modo que o ente central assume as obrigações que não podem, de forma alguma, ser suportadas pelos entes menores. Compreender a essência do princípio da subsidiariedade é, pois, compreender a essência da forma federativa de Estado e das obrigações a ele inerentes, em particular, a proteção do patrimônio histórico na federação. 


\section{CONSIDERAÇÕES FINAIS}

A proteção do patrimônio histórico nacional é um dever estatal de hierarquia constitucional. No quadro das competências administrativas e legislativas, são várias as formas de execução desse dever, o que transfere ao legislador infraconstitucional um considerável espaço de apreciação. Na condição de direito relacionado à personalidade, a proteção do patrimônio histórico possui um lugar de destaque na ordem constitucional, muito embora isso ainda não tenha adquirido a atenção que merece, no mundo real. Por envolver competências concorrentes entre os entes federativos, a questão adquire um grau de complexidade que não pode ser menosprezado.

Entretanto, isso não pode servir de escudo para eventuais omissões tanto por parte do Poder Público quanto da sociedade. É justamente na moderna noção de federalismo cooperativo, ancorada no princípio da subsidiariedade, que a Federação brasileira deve encontrar forças para unir esforços na condução dessa tarefa, tão cara à soberania nacional. $A$ identidade de um povo repousa na sua história e quando a história é perdida, a identidade, em considerável proporção, se esvai.

É por isso que se deve atribuir a todos os entes da federação, com destaque para os Municípios - onde a vida acontece - o papel da proteção do patrimônio histórico brasileiro. Somente uma cultura de concatenação entre todos os entes federados é capaz de dar conta dessa difícil tarefa, considerando a realidade inequívoca de que proteger o patrimônio histórico requer pesados investimentos econômicos. Urge, portanto, priorizar um modelo de descentralização territorial de competências político-administrativas que não conduza a uma centralização excessiva nas mãos da União, em particular do ponto de vista da retenção dos recursos necessários para o cumprimento desse dever constitucional de proteção.

Isso requer uma interpretação direcionada à superação da doutrina dos interesses predominantes do ente central da federação, como limitadores de iniciativas legislativas municipais, para a proteção do patrimônio histórico. Significa que a proteção legislativa deve somar forças e não dividir. Priorize-se o mais benéfico, em detrimento de soluções de índole meramente formal, afinal, o geral não faz sentido sem o particular. Assim, conclui-se que a proteção do patrimônio histórico dos Municípios não pode ser vista apenas como algo de interesse meramente local, já que a cultura regional, em toda sua diversidade, é o que forma, de fato, o belíssimo extrato multicultural nacional.

\section{NOTAS}

1. Matéria prevista no art. $5^{\circ}$, LXXIII da Constituição Federal, regulamentada pela Lei $n^{\circ} 4.717 / 1965$.

2. Art. 193 da CF.

3. Art. 215 da CF.

4. Art. 216, V da CF.

5. STF, ACO 1.966 AgR, Rel. Min. Luiz Fux, j. 17.11.2017, plenário, DJE 27.11.2017.

6. Art. $216, \S 1^{\circ}$ da CF. 
7. Art. $216, \S 4^{\circ}$ da CF.

8. Art. 20, X da CF.

9. Art. 23, III da CF.

10. Art. 23, IV da CF.

11. Nos exatos termos do art. 18 da CF.

12. Art. 30, IX da CF.

13. O art. 24 da CF apenas se refere à atuação da União, dos Estados e do Distrito Federal no âmbito das competências legislativas concorrentes.

14. Art. 30, II da CF.

15. Art. 30, I da CF.

16. Mantida pela Emenda Constitucional n. ${ }^{\circ}$, de 17/10/1969.

17. Art. 24, VII da CF.

18. Art. $24, \S 1^{\circ}$ da CF.

19. Art. $24, \S 2^{\circ}$ da CF.

20. Art. $24, \S 3^{\circ}$ da CF.

21. Art. $24, \S 4^{\circ}$ da CF.

22. Art. 30, II da CF.

23. Hipótese de omissão do ente central na edição de normas gerais em matéria de competência concorrente.

24. STF, ADI 4.228/DF. Rel. Min. Alexandre de Moraes, j. 01.8.2018, Plenário, DJE 13.8.2018.

25. STF, RE 586.224, Rel. Min. Luiz Fux, j. 5.3.2015, Plenário, DJE 8-5-2015, Tema 145.

26. Art. 24, VI da CF.

27. STF, ADI 3.356, Rel. Min. Eros Grau. Rel. para o acórdão, Min. Dias Toffoli. j. 30.11.2017, Plenário, DJE 11.12.2017. O julgamento ocorreu em conjunto com as ADIs 3.357, 3.937 e a ADPF 109.

28. Registre-se que o voto proferido pelo Min. Fachin nos autos da ADI 3.356 foi reajustado para acompanhar o voto final proferido pelo Min. Dias Toffoli, mantendo-se, contudo, a conclusão pela improcedência da ADI.

29. A fundamentação encontra-se referida no informativo nº 848 do STF. Disponível em: <http://www.stf. jus.br/arquivo/informativo/documento/informativo848.htm\#Amianto $\% 20$ e $\% 20$ compet $\%$ C3\%AAncia $\% 20$ legislativa\%20concorrente\%20-\%2014>. Acesso em: 17.8.2018.

\section{REFERÊNCIAS}

ALEXY, Robert. Theorie der Grundrechte. Baden-Baden: Suhrkamp, 1994.

ALMEIDA, Fernanda Dias Menezes de. Competências na Constituição de 1988. 6 ed. São Paulo: Atlas, 2013.

ÁVILA, Humberto. Segurança Jurídica. Entre permanência, mudança e realização no Direito 
Tributário. São Paulo: Malheiros, 2011.

Teoria dos princípios: da definição à aplicação dos princípios jurídicos. 6 ed. São Paulo: Malheiros, 2006.

ATALIBA, Geraldo. Normas gerais de direito financeiro e tributário e autonomia dos Estados e Municípios. Revista de Direito Público. São Paulo: Revista dos Tribunais, ano 2, vol. 10, out.-dez. 1969, p. $45-80$

AZAMBUJA, Darcy. Teoria Geral do Estado. 4. ed. São Paulo: Globo, 2008.

BARBOSA, Ruy. Comentários à Constituição Federal Brasileira de 1891. Colligidos e ordenados por Homero Pires. São Paulo: Saraiva \& Cia, 1934, vol. V.

BARROSO, Luís Roberto. Curso de direito constitucional contemporâneo: os conceitos fundamentais e a construção do novo modelo. 2 ed. São Paulo: Saraiva, 2011.

BLECKMANN, Albert. Staatsrecht II - Die Grundrechte. 4., neubearbeitete Auflage. Köln: Carl Heymanns, 1997.

BONAVIDES, Paulo. Curso de Direito Constitucional. 12 ed. São Paulo: Malheiros, 2002.

BOYSEN, Sigrid. Gleichheit im Bundesstaat. Tübingen: Mohr Siebeck, 2005.

BRANCO, Paulo Gustavo Gonet. In: MENDES, Gilmar Ferreira; BRANCO, Paulo Gustavo Gonet. Curso de Diretio Constitucional. 12 ed. São Paulo: Saraiva, 2017.

CARVALHO PINTO, Carlos Alberto Alves de. Normas gerais de direito financeiro. São Paulo: Prefeitura do Município de São Paulo, 1949.

DALLARI, Dalmo de Abreu. Elementos de Teoria Geral do Estado. 31 ed. São Paulo: Saraiva, 2012.

DUQUE, Marcelo Schenk. Curso de direitos fundamentais: teoria e prática. São Paulo: Revista dos Tribunais, 2014.

Direito privado e Constituição. Drittwirkung dos direitos fundamentais: construção de um modelo de convergência à luz dos contratos de consumo. São Paulo: Revista dos Tribunais, 2013.

O Federalismo Cooperativo Alemão: tendências atuais. In: MARQUES, Claudia Lima; BENICKE, Christoph; JAEGER JUNIOR, Augusto (Org.). Diálogo Entre o Direito Brasileiro e o Direito Alemão: fundamentos, métodos e desafios do ensino em tempos de cooperação internacional. Porto Alegre: Orquestra, 2011, p. 326-368.

ELLWEIN, Thomas. Federalismo e autonomia administrativa: unidade para fora, diversidade para dentro. Um grande triunfo da história alemã. Revista Deutschland. São Paulo, n. 2, abril de 1996, p. 44-49.

FERREIRA FILHO, Manoel Gonçalves. Aspectos do direito constitucional contemporâneo. 3. ed. São Paulo: Saraiva, 2011.

GADAMER, Hans-Georg. Wahrheit und Methode. Grundzüge einer philosophischen Hermeneutik. 6. 
durchgesehene Auflage. Tübingen: Mohr, 1990, Band I.

GRIMM, Dieter. Verfassung. In: GRIMM, Dieter. Die Zukunft der Verfassung. Frankfurt am Main: Suhrkamp, 1991, p. 11-28.

Die Verfassung und die Politik: Einsprüche in Störfällen. München: Beck, 2001.

HESSE, Konrad. Grundzüge des Verfassungsrechts der Bundesrepublik Deutschland. Neudruck der 20. Aufl. Heidelberg: Müller Verlag, 1999.

HORTA, Raul Machado. A posição do Município no Direito Constitucional Federal Brasileiro. Revista de Informação Legislativa. Brasília: Senado Federal, ano 19, n. ${ }^{\circ}$ 75, jul.-set. 1982.

Direito constitucional. 4 ed. rev. e atualizada. Belo Horizonte: Del Rey, 2003.

Organização constitucional do federalismo. Revista de Informação Legislativa. Brasília: Senado Federal, ano 22, n. ${ }^{\circ} 87$, jul.-set. 1985, p. 5-22.

Reconstrução do federalismo brasileiro. Revista de Informação Legislativa. Brasília: Senado Federal, ano 18, n. $^{\circ} 72$, out.-dez. 1981, p. 13-28.

ISENSEE, Josef. Subsidiaritätsprinzip und Verfassungsrecht. Eine Studie über das Regulativ des Verhältnisses von Staat und Gesellschaft. Berlin: Duncker \& Humblot, 1968.

KEWENIG, Wilhelm. Kooperativer Föderalismus und bundesstaatliche Ordnung. Bemerkungen zur Theorie und Praxis des kooperativen Föderalismus in den USA unter besonderer Berücksichtigung der,,grants-in-aid“ der Bundeshilfsprogramme. In: AÖR, Band 93. Tübingen: Mohr, 1968, p. 433-484.

LÜBBE-WOLFF, Gertrude. Die Grundrechte als Eingriffsabwehrrechte. Struktur und Reichweite der Eingriffsdogmatik im Bereich staatlicher Leistungen. Baden-Baden: Nomos, 1988.

MAHONEY, Joan. Constitutionalism, the rule of law, and the cold war. In: CAMPBELL, Tom; EWING, K. D.; TOMKINS, Adam (Ed.). The legal protection of human rights: sceptical essays. New York: Oxford University Press, 2011, p. 127-147.

MARQUES, Claudia Lima. Contratos no código de defesa do consumidor: o novo regime das relações contratuais. 8 ed. rev. e atualizada. São Paulo: Revista dos Tribunais, 2016.

MAUNZ, Theodor; DÜRIG, Günter; et. al. Grundgesetz Kommentar. München: Beck. Band II, 33. Ergänzungslieferung, 1997.

OETER, Stefan. Integration und Subsidiarität im deutschen Bundesstaatsrecht. Untersuchungen zur Bundesstaatstheorie unter dem Grundgesetz. Tübingen: Mohr, 1998.

OLIVEIRA JUNIOR, José Alcebíades. Cultura da Democracia para Direitos Humanos Multiculturais. In: OLIVEIRA JUNIOR, José Alcebíades (Org.). Cultura e Prática dos Direitos Fundamentais. RJ: Lúmen Juris, 2010, p. 3-15.

REVERBEL, Carlos Eduardo Dieder. O federalismo numa visão tridimensional do direito. Porto Alegre: Livraria do Advogado, 2012. 
ŠARČEVIĆ, Edin. Das Bundesstaatsprinzip. Eine staatsrechtliche Untersuchung zur Dogmatik der Bundesstaatlichkeit des Grundgesetzes. Tübingen: Mohr, 2000.

SARLET, Ingo Wolfgang. A eficácia dos direitos fundamentais: uma teoria geral dos direitos fundamentais na perspectiva constitucional. 11. ed. rev. e aum. Porto Alegre: Livraria do Advogado, 2012.

Dignidade da Pessoa Humana e Direitos Fundamentais na Constituição Federal de 1988. 9. ed. rev. e aum. Porto Alegre: Livraria do Advogado, 2012.

SILVA, José Afonso da. Curso de Direito Constitucional Positivo. 25 ed. São Paulo: Malheiros, 2005.

SOUZA JUNIOR, Cezar Saldanha. A Supremacia do Direito no Estado Democrático e seus Modelos Básicos. Porto Alegre: [s.ed.], 2002.

SOUSA, Rubens Gomes de. Normas gerais do direito financeiro. Conferência proferida em 28.8.1953, no Instituto de Direito Público e Ciência Política da Fundação Getúlio Vargas. Disponível em: < $\underline{\text { ttp:// }}$ bibliotecadigital.fgv.br/ojs/index.php/rda/article/viewFile/13996/12877> Acesso em: 10 abr. 2015.

STARCK, Christian. Grundrechtliche Schutzpflichten. In: STARCK, Christian. Praxis der Verfassungsauslegung. Baden-Baden: Nomos, 1994, p. 46-84.

STERN, Klaus. Das Staatsrecht der Bundesrepublik Deutschland. 2. neubearbeitete Auflage. München: Beck, 1984, Band I.

TAVARES, André Ramos. Curso de Direito Constitucional. 16 ed. São Paulo: Saraiva, 2018.

Recebido em: 06/09/2018

Aceito em: 21/09/2018 